\title{
O RURAL E A ESCOLARIZAÇÃO EM PORTUGAL
}

\author{
Justino Magalhães*
}

\begin{abstract}
RESUMO
A escola portuguesa estabeleceu com a sociedade uma relação qualitativamente diferenciada. $\mathrm{O}$ rural foi representado como arcaico, subdesenvolvido e de inevitável transformação por contraponto ao mundo urbano culto e progressista, apresentado como norma. Este estudo permite demonstrar que, não obstante, a subalternização da cultura e do modelo de desenvolvimento rural, houve uma política educativa e uma pedagogia orientadas para o mundo rural. Destinados à alfabetização das populações rurais, o Estado Novo criou a figura do Regente Escolar e ampliou a oferta educativa com Postos Escolares. A alfabetização rural era o primeiro grau da Escola Única. Assim, em resposta ao inquérito Possibilités d'Accès à l'Éducation dans les Zones Rurales (1958), o governo português reiterou a ideia de que em Portugal a Escola é a mesma para todos.
\end{abstract}

Palavras-chave: Escola Portuguesa. Escola Única. Mundo Rural.

\begin{abstract}
The Portuguese school established with the society a relation qualitatively differentiated. The agricultural one was represented as archaic, underdeveloped and of inevitable transformation for counterpoint to the cultured and progressive urban world, presented as norm. This study it allows to demonstrate that, not obstante, the subaltern condition of the culture and the model of agricultural development, had one guided educative politics and a pedagogy for the agricultural world. Destined to the literacy of the agricultural populations, the New State created the figure of the School Regent and extended offers educative with School Offices. The rural literacy was the first degree of the Unique School. Thus, in reply to the inquiry Possibilités d'Accès to the l'Éducation dans
\end{abstract}

\footnotetext{
* Doutor em História da Educação pela Universidade do Minho, Braga, Portugal. Professor Catedrático do Instituto de Educação da Universidade de Lisboa, Portugal. E-mail: justinomagalhaes@ie.ul.pt
} 
les Zones Rurales (1958), the Portuguese government reiterated the idea of that in Portugal the School is the same one for all.

Keywords: Portuguese School. Unique School. Rural World.

1. A relação que, em Portugal, a escola estabeleceu com a sociedade foi qualitativamente diferenciada e o rural foi representado como arcaico, subdesenvolvido e de inevitável transformação. A escola, tendo muito cedo definido uma vulgata informativa de referente erudito e incorporado uma pragmática urbana (configurados numa oficialização letrada), não facilitou os mecanismos de acesso, remediação, significação. Num país onde, na viragem de Oitocentos, a agricultura absorvia $60 \%$ da população e havia $40 \%$ de analfabetos, não houve uma resposta escolar diferenciada para os universos urbano e rural.

A historiografia da educação tem aqui algum contributo. Diferentes aspectos estão subjacentes à conveniência de equacionar uma relação escola-sociedade que vise ilustrar e dar a conhecer como a escola única portuguesa foi frequentemente objecto de contestação e de proposta de mudança. A acção e o produto escolar junto do mundo e da sociedade rural se não foram específicos também não foram uniformes.

2. A temática da história do ensino primário é central à Modernização ocidental e, por consequência, à modernização portuguesa, cuja evolução decorreu com assinaláveis variações na socialização da escrita, na progressão curricular, e de segmento escolar para segmento escolar. Tais variações não permitem todavia iludir a manutenção de uma continuidade e de uma regularidade. Por outro lado, não deixam iludir ou despir de sentido a constatação de que convergem sobre a ruralidade e, por vezes, com a mesma perspectiva, olhares de diferentes disciplinas.

Poder-se-á perguntar se tais convergências resultam de transversalidades de uma mesma interpretação ou se, apesar da variação, não fazem parte de conceptualização comum. De idêntico modo, é possível atender a uma continuidade conceptual ou orgânica de período histórico para período histórico. Desta continuidade ressalta uma segregação ou mesmo a ocultação do rural, subsumido no ideário e no currículo oficioso da escola única. 
Uma leitura sistemática e crítica dos exemplares da revista Escola Portuguesa publicados no quinquénio de 1934 a 1939, período que corresponde à institucionalização do Estado Novo, permite comprovar que o rural era assunto de abordagem frequente, ainda que apresentado de forma indirecta. Uma dessas referências indirectas era a contraposição ao mundo urbano, apontado como perigoso e imoral. A análise da Escola Portuguesa permite de igual modo inferir que, pelo estatuto de periódico oficioso destinado a informar e normalizar, era aos profissionais espalhados pelo mundo rural que, verdadeiramente, se destinava esta revista.

Partindo da história da educação, observa-se que houve em torno da escolarização do rural uma diversidade de perspectivas, dependendo dos níveis de ensino e dos modos de descrever e apresentar o mundo e a realidade rural no plano curricular. A diversidade reporta também à variação de olhares, em função das distintas perspectivas pedagógicas e científicas. Da alfabetização às classes avançadas, o modo de incorporação variou: descrição, comparação, modelo. No plano disciplinar, é possível inventariar estudos e investigadores que tomaram em atenção a especificidade do rural, gerando uma construção semântica própria, ainda que nem sempre inteiramente distinta da do mundo urbano. Há estudos e investigadores que, aplicando marcos conceptuais gerais e fazendo uso de instrumentos analíticos comuns, demonstraram e ilustraram a existência de características típicas do mundo rural.

A historiografia não é uníssona sobre o rural. Também o mundo rural não foi uniforme, nem de conjuntura para conjuntura, nem no âmbito de uma mesma conjuntura. No plano curricular, pode aventar-se uma tónica geral: os textos, os tópicos e os programas escolares tendem a representar o rural como tradição e mundo a descobrir. O processo escolar inclui descrições e visitas de estudo, que tanto acentuam o contraste com a realidade urbana quanto caracterizam o rural como um tempo e um modo de vida saudável, idílico.

O dossier agora publicado, composto por estudos e temáticas não inteiramente sobrepostas, nem no tempo, nem na perspectiva metódica, intenta provar, nomeadamente no que reporta a aspectos de comunalidade e a contrastes, que o tempo dos governos centralizados e totalitários, ditos Estado Novo, não foi uniforme, nem quanto à representação científico- 
pedagógica do rural, nem quanto à inclusão do rural no currículo escolar. Em contrapartida, é possível encontrar alguma constância sobre a preservação do rural, para além da vigência desses regimes. Assim, na década de sessenta, perante o êxodo para as cidades em busca de melhoria da qualidade de vida e em face da consequente melhoria das infra-estruturas, ocorreu o fomento do rural como descoberta e itinerário turístico. No entanto, tal revisitação foi publicitada e orientada por textos, legendas e tópicos colhidos nos discursos escolares. Apesar de os principais destinatários dessa propaganda serem oriundos do mundo urbano (ou porventura por isso mesmo), os roteiros não abriam para novas descobertas.

Não menos notório que a cristalização dos olhares sobre o rural é o silêncio a que, por vezes, foi votado. O presente dossier ilustra tanto a singularidade quanto o silêncio, pois que, além dos diferentes olhares, reporta os diferentes tempos e modos de esquecimento. No que respeita, por exemplo, à formação de professores e à pedagogia escolar, constata-se que, ao contrário daquilo que foi desde cedo assumido no Brasil, em Portugal houve, no plano formal, uma quase-ignorância do rural como mundo com autonomia e destino próprio. Uma aproximação sumária ao ideário da reforma escolar iniciada com a Ditadura Militar e prosseguida com o Estado Novo permite evidenciar alguns aspectos, onde a ruralidade foi tomada como objectivo. Um desses aspectos, em que houve continuidade da Ditadura Militar para o Estado Novo foi a ampliação da oferta escolar através da multiplicação de estruturas elementares, senão mesmo precárias, e de funcionamento temporário, disseminadas pelo país rural. As escolas temporárias da Ditadura Militar foram sendo substituídas por Postos Escolares, que eram pequenas unidades de ensino caracterizadamente rurais, confiados à figura do Regente Escolar.

3. No final da década de 20 do século $\mathrm{XX}$, em vigência da Ditadura Militar, teve lugar uma polémica em torno da alfabetização, com origem e repercussões na escolarização das populações rurais. Sendo o país basicamente rural, os núcleos urbanos estavam, de uma forma geral, servidos de escolas elementares e, em alguns casos, complementares. A distinção entre urbano e rural acentuava-se no que respeitava à falta de oportunidade escolar, como também na desvalorização da formação escolar. 
Para os estratos da população mais empobrecidos, mesmo que urbanos, e para uma parte significativa das populações rurais, o saber ler, escrever e contar, quer obtidos de modo informal, quer através da frequência escolar, não se traduziam necessariamente numa melhoria de vida. Tal desinteresse era frequentemente utilizado por parte das autoridades responsáveis como justificação para não criarem oportunidades para a alfabetização.

$\mathrm{O}$ escritor Aquilino Ribeiro, conhecedor da realidade e da mentalidade dos 'rústicos' e partidário incansável da cultura e do progresso como meios de humanização, interviera, no início do ano de 1927, numa contenda de ideias, em benefício da alfabetização e das virtualidades antropológicas e sociais da aculturação escrita. Fizera-o, reagindo ao editorial, de 9 de Janeiro, de $O$ Século. Nesse editorial, era reconhecido que "a vaga de analfabetismo que sufoca a sociedade portuguesa é intolerável. Constitui para este país uma vergonha sem nome" e, apesar dos esforços da República, "a situação de Portugal, no campo do ensino primário, é mais que humilhante, porque chega a ser vexatória". Aproveitando o ensejo, Aquilino Ribeiro publicou, no editorial, de 10 de Janeiro, do mesmo jornal, um artigo polémico que intitulou "Do absurdo de criar escolas". Nesse artigo, procurou demonstrar as anacronias do processo de desenvolvimento histórico de inspiração exógena, contrapondo os mundos rural e urbano. Relativamente ao primeiro, afirmou:

Todos nós, que nos criámos hábitos de civilizados, nos lastimamos a justo título das estradas que não são mais que ravinas, quando deviam ser alcatroadas, das escolas que não são suficientemente sumptuosas para ensinar os nossos filhos a ser gente, de todo esse pseudo-progresso bunda, reles, caótico, com que andamos a presumir europeus". [Mas] A aldeia portuguesa - o Norte, salvo a mancha das cidades e das vilas parasitárias - é isto, um conglomerado triste, selvagem, paupérrimo, que ofende toda a criatura de bem, que tenha o sentimento de solidariedade, já não digo humana, mas de raça. ${ }^{1}$

A causa desta situação tem sido atribuída à falta de instrução. No entanto, este escritor - ele que, nas suas obras, glosou a sabedoria do mundo

1 In O Século, 10 de Janeiro de 1927. 
rural e recriou os mais profundos traços de carácter, virtude e honra, que embelezavam a alma desses rústicos - advertiu que "a escola, por si só não resolve o problema do analfabetismo". Antes a questão deveria ser colocada na utilidade dessa aprendizagem. Desafiando o leitor, interrogava-se: "Para quê aprender a ler e a escrever naqueles lugares onde não há necessidade de ler e escrever?". E antes que a resposta surgisse ambígua, empenhava a sua autoridade de humanista e voz do progresso, afirmando:

No dia em que saber ler e escrever lhe seja tão útil como saber governar o arado, plantar feijões, ou até jogar o pau, nesse dia as escolas, as más anti-higiénicas e lôbregas escolas de Portugal abarrotarão de estudantes. Essa utilidade, é intuitivo, só pode obter-se mercê de medidas gerais de fomento, estradas, caminhos-de-ferro, indústrias e mais aquisições da vida moderna, coisas estas, com o alfabeto, confluentes e conexas dum só progresso. ${ }^{2}$

No combate pela extinção do analfabetismo, foi frequente a confusão entre aculturação escrita e escolarização, uma vez que as causas do analfabetismo eram atribuídas à inexistência de escolas. As Escolas Móveis, que vieram a ser extintas pelo Decreto n. ${ }^{\circ} 18819$ de 5 de Setembro de 1930, tinham cumprido um papel de ampliação de alfabetização dos adultos, ainda que, também elas, não tenham ido muito para além de núcleos urbanizados das sedes de concelho. Nos termos deste Decreto, passava a ser autorizada a criação de escolas temporárias nas povoações que tivessem, no mínimo, 30 crianças em idade escolar. Para que essas escolas funcionassem, bastaria que a leccionação fosse assegurada por uma pessoa que "possu[ísse] a necessária idoneidade moral e intelectual".

No oposto do voluntarismo escolar, se bem que assegurando o nível elementar de alfabetização, e de modo bem distinto do sentido humanista da aculturação escrita, como a entendeu Aquilino Ribeiro, estavam correntes de opinião defensoras da preservação do arcaísmo e do isolacionismo rurais, como reserva do nacionalismo e da moralidade. A escola era interpretada como meio de fuga.

\footnotetext{
2 Ibideam.
} 
A década de 30 foi de afirmação do Estado Novo, foi também uma década de fomento rural, com campanhas como a do trigo. A política de fixação das populações levou a que o aproveitamento agrícola atingisse o limite do solo arável. Dando consequência ao fomento agrícola e à ruralização, na reorganização das estruturas administrativas do Estado Novo, a Lei n. ${ }^{o}$ 1918, de 27 de Maio de 1935, continha as Bases do Ensino Rural. Tal ensino era destinado a transmitir noções gerais de agricultura e deveria variar de região para região. A lei, que não chegou a ser regulada, retomava um debate que vinha dos anos anteriores: o da escola regional.

A ideia de escola regional surgia como contraponto e, de algum modo, como negação à escola única, e particularmente ao conceito de Escola Única do Trabalho, defendida por alguns sectores progressistas, entre os quais António Sérgio. Na transição da década de XX, o debate era intenso, mas não foi inteiramente consequente. A escola regimentalizada do Estado Novo foi acomodada ao destino pátrio e reduzida a um minimum sociocultural. A ideia de reserva do mundo rural foi sendo mantida por diversos meios.

No n. ${ }^{\circ} 327$ da Escola Portuguesa, datado de 30 de Janeiro de 1941, vinha transcrita uma circular da Direcção-Geral do Ensino Primário, em que era considerado pernicioso "o errado conceito, que nos meios rurais se formou, de que só nos centros citadinos se encontra o bem-estar, como o é a fuga para estes dos elementos necessários à prosperidade das terras em que nasceram". De acordo com o discurso oficial, os aldeãos tomavam a escola como meio de libertação, pois que

(...) a caneta era para eles a nova enxada, que não caleja as mãos nem lança terra para as costas e dá mais e melhor que comer. Se a escola coopera nestas loucas aspirações paternas, torna-se elemento prejudicial ao meio por alimentar o vício do urbanismo, rarefazendo de braços úteis a terra, que, sem eles, empobrece ${ }^{3}$.

3 Apud J. Salvado Sampaio. O Ensino Primário 1911-1969. Contribuição Monográfica. Volume II (2º Período - 1926-1955). Lisboa: Instituto Gulbenkian de Ciência/ Centro de Investigação pedagógica, 1976, pp. 48-49. 
A reserva moral e de regime com que foi contemplado o mundo rural correspondia a uma incapacidade do país em regenerar-se e modernizar-se. A extensão colonial surgia como prolongamento do regime corporativo assente numa forte hierarquia social, contraponto à Europa e ao Ocidente escolarizado, culto, tecnológico, urbano e enriquecido.

4. A ampliação escolar através da multiplicação de Postos Escolares foi apresentada como medida económica e tendente a multiplicar rapidamente o número de alfabetizados. $\mathrm{O}$ mais controverso, porém, foi o processo de recrutamento dos docentes, que, sem uma formação prévia (curricular ou pedagógica), eram inseridos na instituição escolar. $\mathrm{O}$ recrutamento dos Regentes era feito através da aprovação em exame de habilitação correspondente à Instrução Elementar, o que nem assegurava que tivessem tido um percurso escolar, nem que soubessem leccionar. $\mathrm{O}$ resultado da acção docente dos Regentes corresponderia a uma alfabetização elementar, que para a generalidade dos alunos se tornava inconsequente para a prossecução de estudos.

Pelo Relatório que a inspectora Áurea Judite do Amaral enviou ao Director Geral do Ensino Primário, relativo aos Exames de aptidão para Regentes dos Postos de Ensino, realizados em Viana do Castelo, entre 25 de Agosto e 1 de Setembro de 1936, fica-se informado que concorreram 54 candidatos, sendo 27 do género masculino e 27 do género feminino, e que foram aprovados 22 candidatos, sendo 15 do género masculino e 7 do feminino. Reprovaram cerca de $55 \%$ dos candidatos. Procurando uma interpretação para aqueles resultados, a Inspectora não atenta propriamente na percentagem global de reprovações, mas na discrepância entre o género masculino e o feminino, que atribui ao facto de que, "na maior parte, os candidatos pertenceriam ao meio rural, onde a cultura das raparigas é, por via de regra, mais descurada. Aí deve estar a diferença; os candidatos do sexo masculino tinham maior cultura"4. Em idênticas circunstâncias, o Inspector que presidiu aos exames no distrito de Bragança relatou que foram admitidos à Prova 36 candidatos ( 5 do género masculino e 31 do feminino), tendo sido aprovados apenas $28 \%$. Assim portanto, a endogenia

4 Escola Portuguesa, Ano III, nº 105, 22/10/1936. 
do mundo rural não seria auto-suficiente para a regeneração escolar. O ensino escolar incide sobre a norma linguística e era, sobretudo, em língua materna que se acentuavam as falhas dos examinados.

Na Lei n. ${ }^{\circ}$ 1969, de 20 de Maio de 1938, que continha as bases da Reforma do Ensino Primário, ficava reiterado que os Postos Escolares não eram Escolas. Ficava aberta a possibilidade de, no final de cinco anos de trabalho, os Regentes poderem requerer Exame de Estado, no qual seria tomada em atenção a experiência pedagógica e a formação entretanto obtida. Como princípio geral ficava estipulado que a habilitação de professores e regentes "terá sentido imperial, corporativo e predominantemente rural, abrangerá aprendizagem dum ofício e, na medida do possível, a prática da psicotecnia, para se descobrir a aptidão natural dos alunos"'.

A ruralidade estava presente na formação de professores e no ideário escola mas de forma mitigada. A apologia do rural e a sua lenta evolução, ainda que povoada por pólos urbanizados cada vez mais notórios na paisagem, prolongou-se no imediato Pós-Guerra, mas tornou-se insustentável a partir de final dos anos 50 .

No Recenseamento Geral da População, em 1960, era tomado como centro urbano "a capital de distrito e a localidade qualquer que fosse a sua categorialegal (cidade, vila, etc.) que, naárea urbana, demarcada pela Câmara Municipal respectiva, contasse 10000 ou mais habitantes". De acordo com esta classificação, a grande maioria da população portuguesa era rural.

5. O rural, como realidade assimétrica endógena, contraponto do urbano, e como alternativa e objectivo de desenvolvimento, era entretanto objecto de uma preocupação internacional acrescida, coordenada pela UNESCO. Não apenas a generalidade dos países em vias de desenvolvimento emergiam de uma economia basicamente agrícola, como a ruralidade era progressivamente interpretada como sinónimo de pobreza e conservadora das assimetrias sociais e das hegemonias internacionais.

Um inquérito da Unesco, designado Possibilités d'Accès à

5 Apud Sampaio, op. cit., p. 69.

6 INE. Recenseamento Geral da População, 1960. Volume II, p. VII. 
l'Éducation dans les Zones Rurales ${ }^{7}$, a que responderam 71 países, revela, como conclui Roger Girod (membro da Divisão de Investigação do Bureau International d'Éducation), que "tous les pays qui ont répondu à l'enquête s'efforcent de diminuer l'écart qui sépare les populations rurales des autres en matière d'éducation". Os textos legislativos da generalidade dos países eram os mesmos para as populações rurais e para as urbanas, ainda que em alguns países as actividades escolares fossem orientadas, nuns locais para actividades agrárias e noutros para a indústria em sentido amplo. Com base nos dados obtidos, os autores do comentário ao relatório, aventavam a hipótese de que os países

(...) dans lesquels tous les enfants normaux des zones rurales vont à l'école primaire et y restent autant d'années que ceux des villes doivent comprendre à peu près de tiers de la population mondiale totale et seulement une fraction bien moindre de le population rurale du globe. Il s'agit en effet des pays les plus industrialisés. ${ }^{8}$

A escolarização acompanha assim o desenvolvimento e são os países mais industrializados que apresentam uma escolarização universal. No que reporta aos planos de estudo, a generalidade dos países mantinha os mesmos programas em todo o território, mas com adaptação ao meio - casos dos Estados Unidos da América, Suíça, Reino Unido, e como sucedia nos Países da América do Sul. No caso da União Soviética, eram consideradas as diferenças nos Abecedários e na orientação para a produção. No que refere à remuneração, em muitos países, os mestres do mundo rural recebiam um reforço de salário. Muitos países havia, que sustentavam transportes escolares e apoios sociais às crianças com menos facilidade de acesso à escola. Vários países (como os Estados Unidos da América e a Espanha) estavam a implementar sistemas de concentração dos alunos em centros escolares.

As autoridades portuguesas deixaram sem resposta a generalidade dos itens, talvez por não os considerarem ajustados. Àqueles a que

7 UNESCO. Possibilités d'Accès à l'Éducation dans les Zones Rurales. Paris/ Genève: Unesco/ Bureau International d'Éducation, 1958.

8 Idem, p. 13. 
responderam, como foi o caso do item referente aos Planos Escolares, ficou gravada a resposta lacónica de "aucune différence". Assim portanto, um país que considerava como rural a maioria da população, apresentava uma diversidade económica progressivamente mais reconhecida entre o Portugal Rural, o Litoral e o Urbano. Não reconhecia, todavia, qualquer tipo de diferenciação escolar positiva em face das assimetrias entre o rural e o urbano. A confusão entre escola única e escola portuguesa continuava a impedir o ajustamento curricular. Do receio do "terceiro instruído", para fazermos uso da expressão tão cara a pensamentos críticos como o de António Sérgio e o de Michel Serres, continuava a resultar afinal um "terceiro dominado".

Data de registro:13/05/2013

Data de aceite: 08/07/2013

$9 \quad$ Idem, p. 15. 